\title{
Apical root resorption caused by orthodontic forces: A brief review and a long-term observation
}

\author{
Ahu Topkara ${ }^{1}$ \\ Ali I Karaman ${ }^{2}$ \\ Chung $\mathrm{H} \mathrm{Kau}^{3}$
}

\begin{abstract}
External apical root resorption (ARR) is a common iatrogenic consequence of orthodontic treatment. One of the aims of this article is to present a brief overview of the literature, including; diagnosis and etiology, with emphasis on orthodontic forces to facilitate an understand of the prevention or management of ARR in orthodontic patients. We also present a long-term follow-up observation of severe ARR, including the last obtained cone beam computed tomography (CBCT) records, to demonstrate the effect of orthodontic forces on ARR. (Eur J Dent 2012;6:445-453)
\end{abstract}

Key words: Root resorption; orthodontic treatment; orthodontic forces; follow- up case

\section{INTRODUCTION}

External apical root resorption (ARR) is an undesirable complication of orthodontic treatment that results in permanent loss of tooth structure from the root apex. However, it can be avoided with more accurate management of orthodontic treatment. The literature indicates that patients undergoing orthodontic treatment are more likely to have severe ARR..$^{1-4}$ While this is not the only factor responsible for ARR, the effect of orthodontic treatment can be a major trigger. ${ }^{2,5}$ Thus, it is important to understand the role of orthodontics in

Private practice, Orthoclinic, Alanya, TURKIYE

2 Department of Orthodontics, Kocaeli University, Kocaeli, TURKIYE

3 Department of Orthodontics, University of Alabama, Birmingham, Alabama, USA

- Corresponding author: Dr. Ahu Topkara Gullerpinari Mah. E. Kahvecioglu Cad. No:6/2 07400, Alanya TURKIYE

Tel/Fax: +902425136043

Email: ahutopkarađgmail.com the occurrence of ARR. Greater knowledge derived from high-quality research will help minimize the harmful effects and decrease the root resorption observed in ARR.

\section{CURRENT KNOWLEDGE OF ARR}

\section{Etiology}

The etiology of ARR is multifactorial; these factors consist of individual biologic characteristics, genetic predisposition and the effect of orthodontic forces. ${ }^{2-7}$ Risk factors for ARR can be categorized as patient-related and treatment-related. Patient-related factors include; genetics, systemic factors, asthma and allergies, chronic alcoholism, the severity of malocclusion, tooth-root morphology, a previous history of root resorption, alveolar bone density, root proximity to cortical bone, endodontic treatment, and patient age and sex. Orthodontic treatment-related risk factors include; the treatment duration, magnitude of applied force, direction of tooth movement, amount of apical displacement, and method of force application. ${ }^{2}$ 


\section{Prevalence and Diagnosis}

ARR occurs in different degrees. Severe ARR is defined as a shortening that is more than $4 \mathrm{~mm}$ or one-third of the root length and is observed in $1 \%-5 \%$ of teeth. ${ }^{2,4,8}$ Histologic research indicates an extremely high (more than 90\%) occurrence of root resorption that is caused by orthodontic forces. 2,9 However, radiological incidence is lower than histological incidence. ${ }^{10}$ In a recent study by Marques et al, the incidence of severe ARR of the incisors after orthodontic treatment was found to be $14.5 \% .{ }^{11}$ The most commonly used diagnostic techniques are panoramic or periapical radiography. In a recent study by Dudic et al, which compared panoramic radiography with cone beam computed tomography (CBCT), significant differences were found between the two methods: $56.5 \%$ and $31 \%$ of the teeth displayed no resorption in panoramic radiography and CBCT, respectively. ${ }^{12}$ Results show that ARR after orthodontic treatment is underestimated when evaluated with panoramic radiography.

\section{Effects of Orthodontic Forces}

Studies indicate that orthodontic forces have considerable influence on the occurrence of root

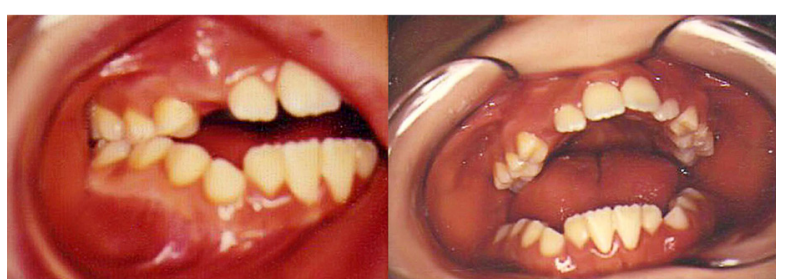

Figure 1. Initial intraoral photographs, taken in 1989 resorption. ${ }^{13-16}$ It has also been demonstrated that heavy forces produced significantly more root resorption than light forces. ${ }^{13,14,16,17}$ When considering the direction of force and tooth movement in the occurrence of root resorption, Chan and Darendeliler indicated that compressive forces cause more resorption than tensile forces. ${ }^{16}$ Han et $\mathrm{al}^{18}$ also concluded that the intrusion of teeth causes about four times more root resorption than extrusion; however, it should be noted that the extrusion of teeth may also cause ARR in susceptible individuals. Intrusive forces together with lingual root torque and jiggling movement remain the most influential forces in causing ARR. ${ }^{2,18-20}$

The duration of force application or active treatment is also one of the risk factors related to orthodontic treatment. Segal et $\mathrm{al}^{21}$ indicated that factors associated with the duration of active treatment might result in increased levels of ARR, and it was concluded that the apical displacement and total treatment duration proved to be highly correlated with the mean ARR. It was suggested that 2 to 3 month pauses in force, achieved with a passive arch wire,

Minimises further root resorption. ${ }^{2}$ Levander et $\mathrm{al}^{22}$ showed that the amount of root resorption is significantly less in patients who are treated with such pauses than in those treated without an interruption. Acar et $\mathrm{al}^{23}$ also indicated that the application of discontinuous force results in less root resorption than does the application of continuous force. This situation can be explained by the fact that a pause in the force allows the resorbed

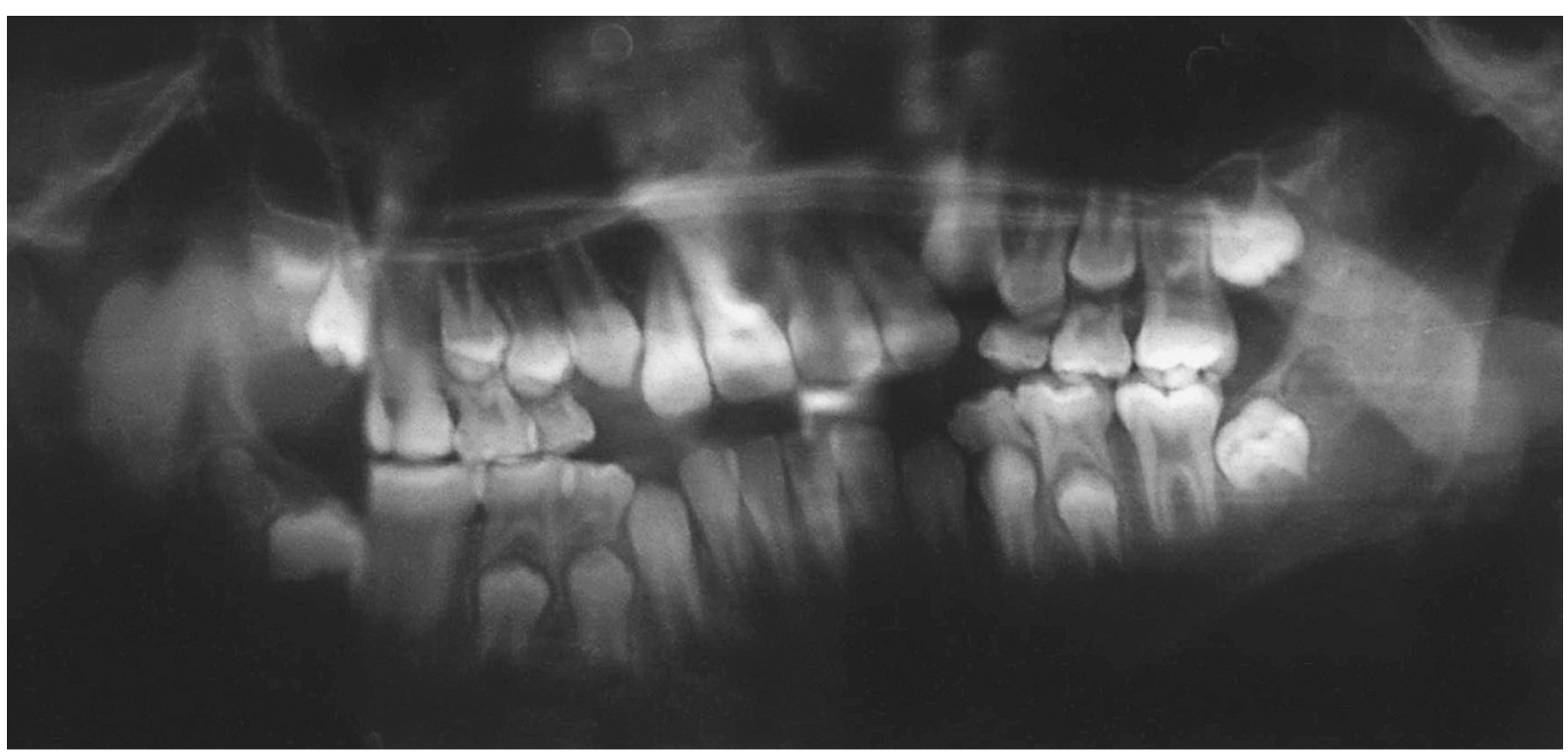

Figure 2. Initial panoramic radiograph, taken in 1989. 


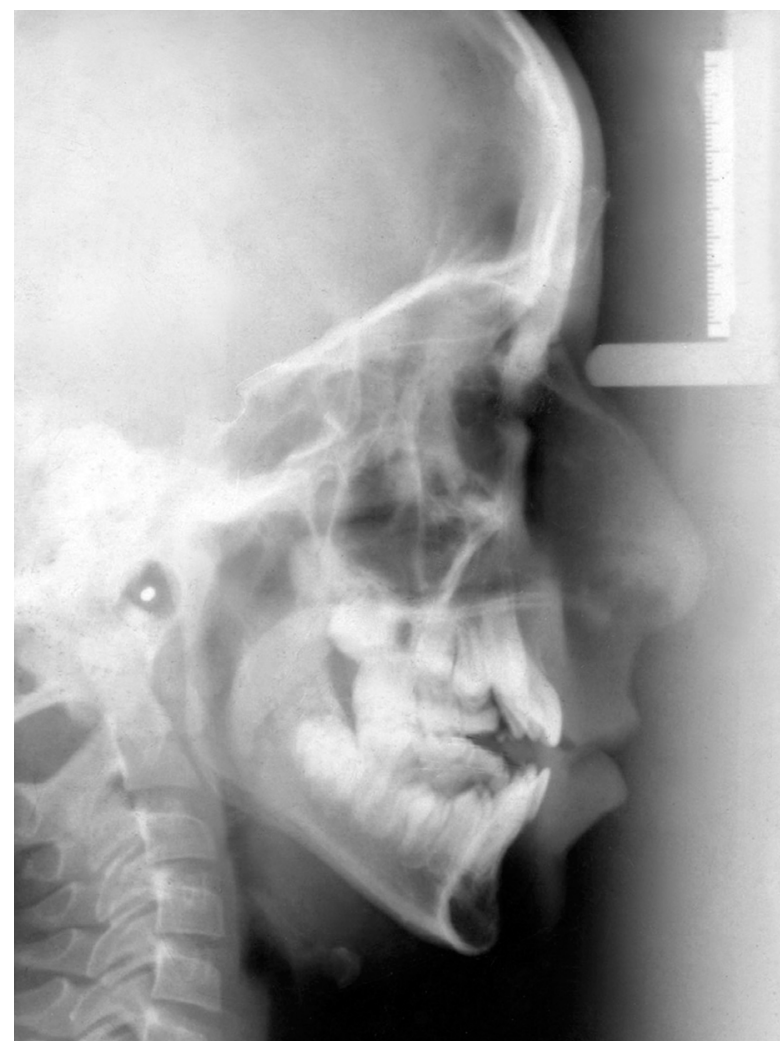

Figure 3. Initial cephalometric x-ray, taken in 1989. cementum to heal and prevents further resorption. ${ }^{24,25}$

\section{A 21-YEAR FOLLOW-UP OBSERVA- TION}

This study outlines the prognosis of a case of severe apical root resorption (ARR) in a patient with an open bite who was subjected to extremely long-term orthodontic treatment.

A 10-year-old boy presented to a university hospital for orthodontic treatment with the following findings:

- Skeletal and dental Class I malocclusion

- Vertical growth and a high mandibular plane angle

- Severe anterior and bilateral open bite

- Sigmatism la speech impediment characterized by faulty pronunciation of sibilant sounds)

- Mouth breathing, habitual tongue thrust, and incompetent lips

- Maxillary arch length deficiency

- A medical history of allergic reactions

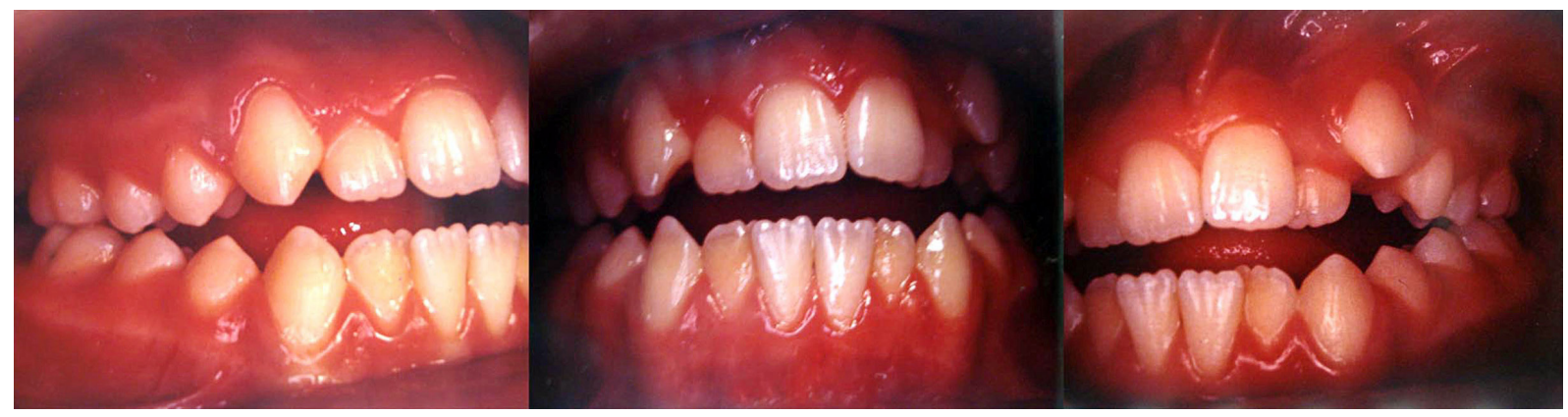

Figure 4. Intraoral photographs after Frankel IV therapy in 1991

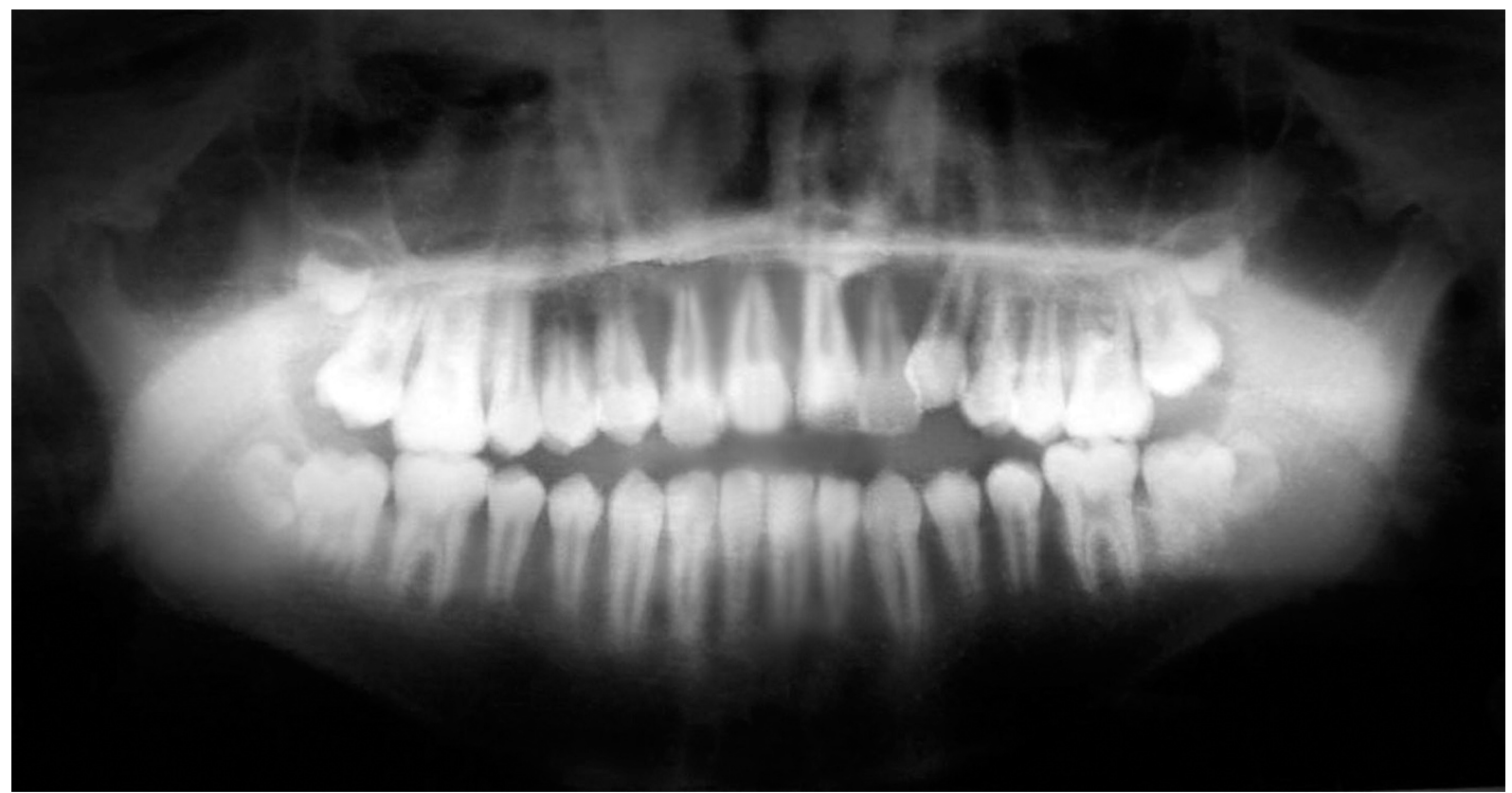

Figure 5. Panoramic x-ray taken before fixed appliance treatment in 1991. 


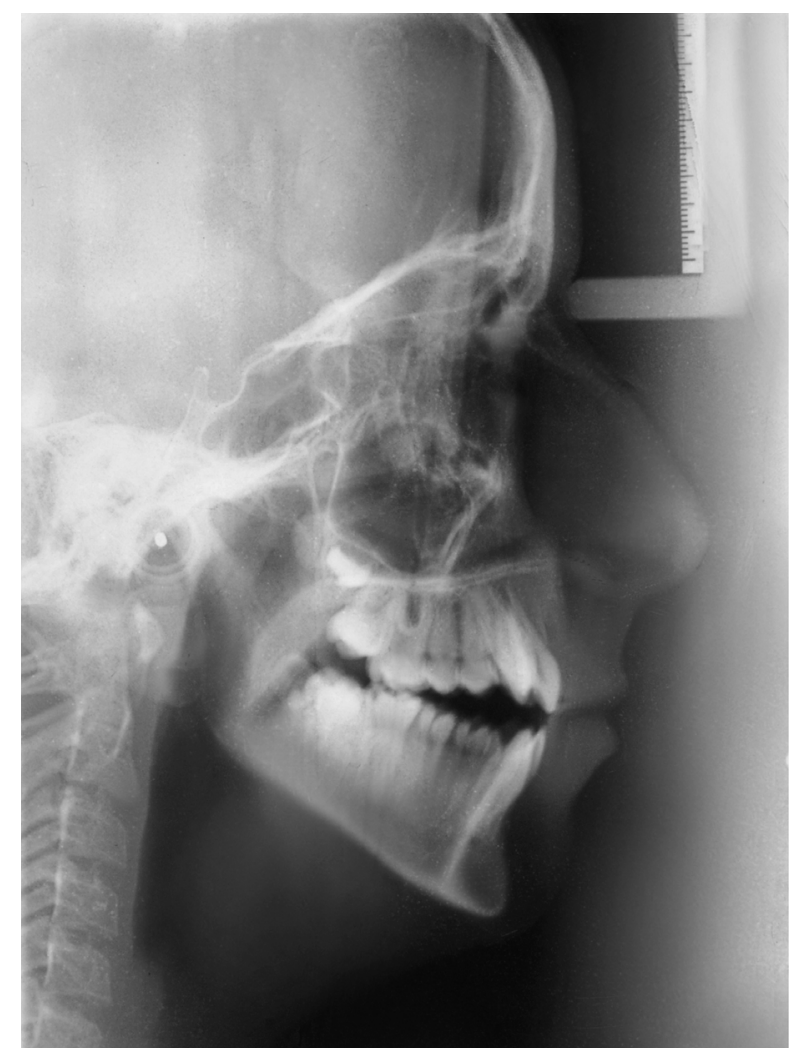

Figure 6. Cephalometric x-ray taken before fixed appliance treatment in 1991.
- A family history of allergies and asthma

After evaluation of the patient (Figures 1-3), Frankel IV appliance therapy was immediately initiated; this course of treatment began in 1989. After two years, the patient still had an anterior and bilateral open bite with occlusal contacts solely on the molars (Figures 4-6). As seen on the panoramic $x$-ray, the transition from mixed dentition to permanent dentition was completed in 1991 (Figure 5). However the apexification of some teeth was still progressing.

The fixed appliance therapy was planned along with four first premolar extractions in 1991. Treatment with straight wire appliances was initiated, followed by rapid maxillary expansion and premolar extractions. Treatment was completed with a good occlusion and aesthetics (Figures 7-9). However, there was some degree of ARR in almost every tooth, clearly visible on the panoramic radiograph from 1994 (Figure 8). The teeth most affected by severe ARR were the upper and lower incisors and the upper first molars.

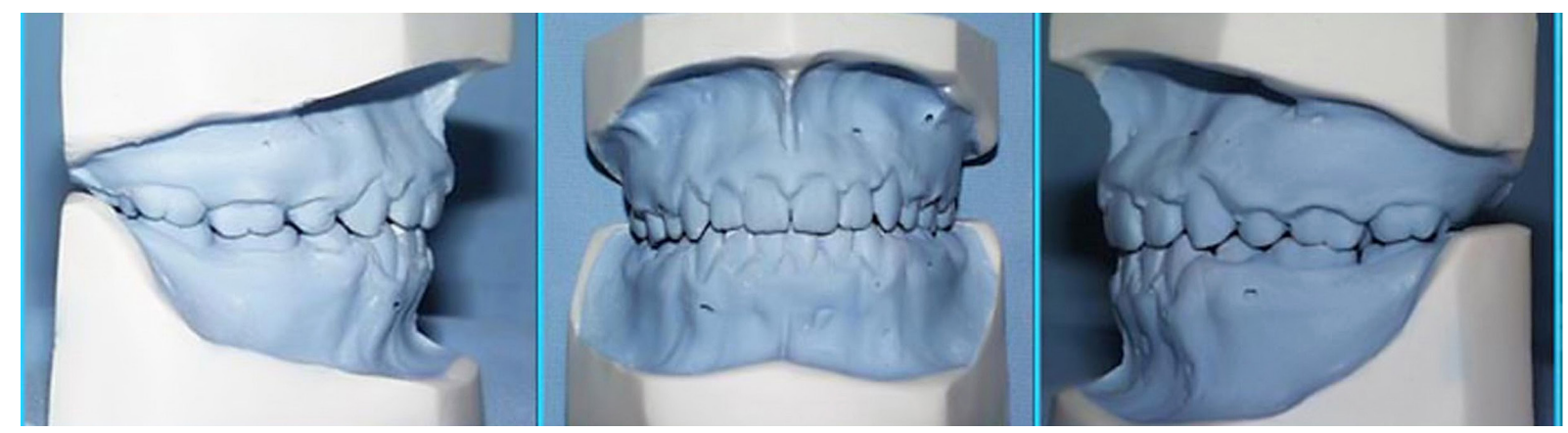

Figure 7. Post-treatment dental casts, obtained in 1994.

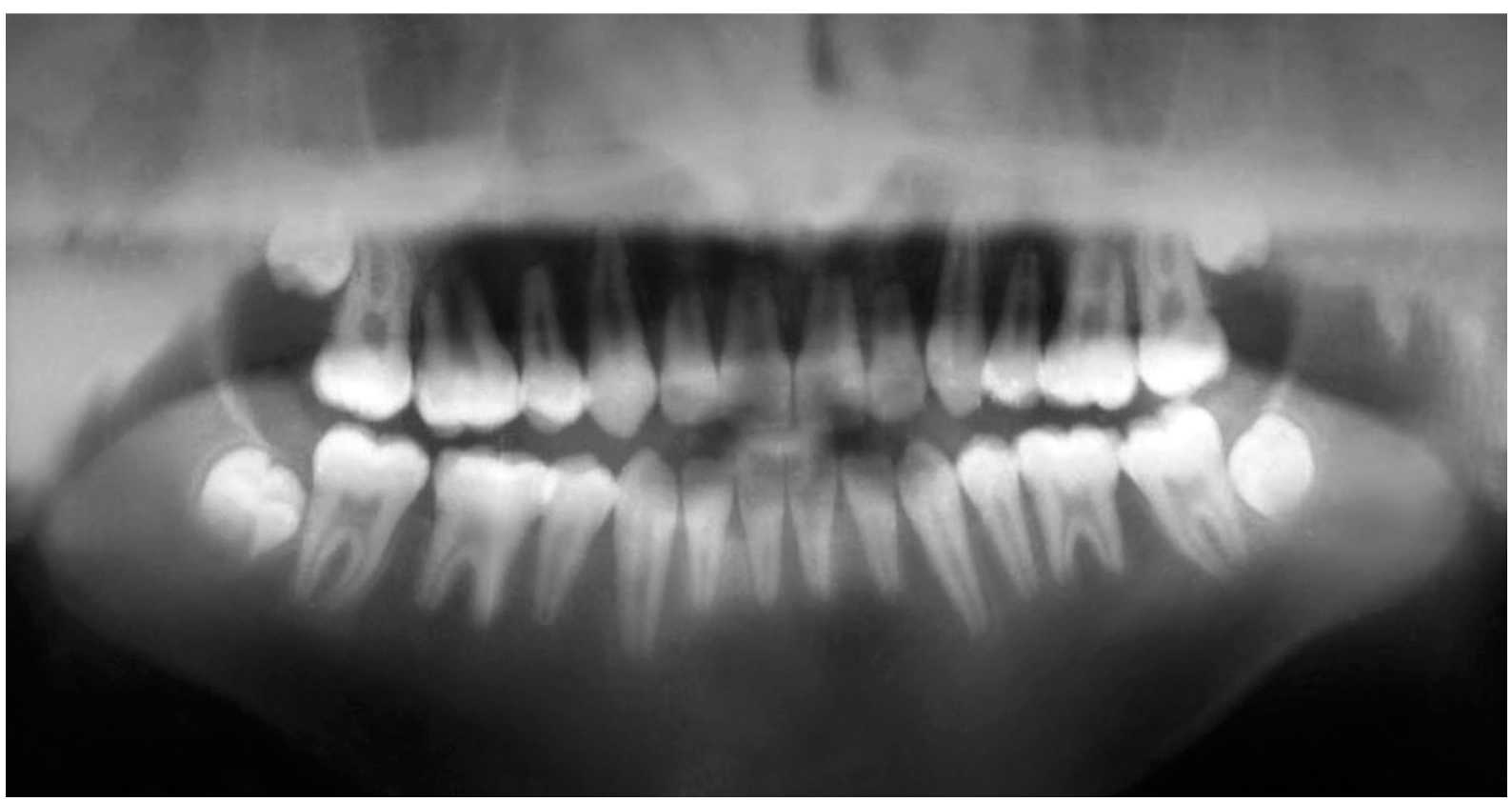

Figure 8. Post-treatment panoramic x-ray, taken in 1994. Clearly visible ARR. 
The patient came back to the hospital approximately one year later with a degree of open bite

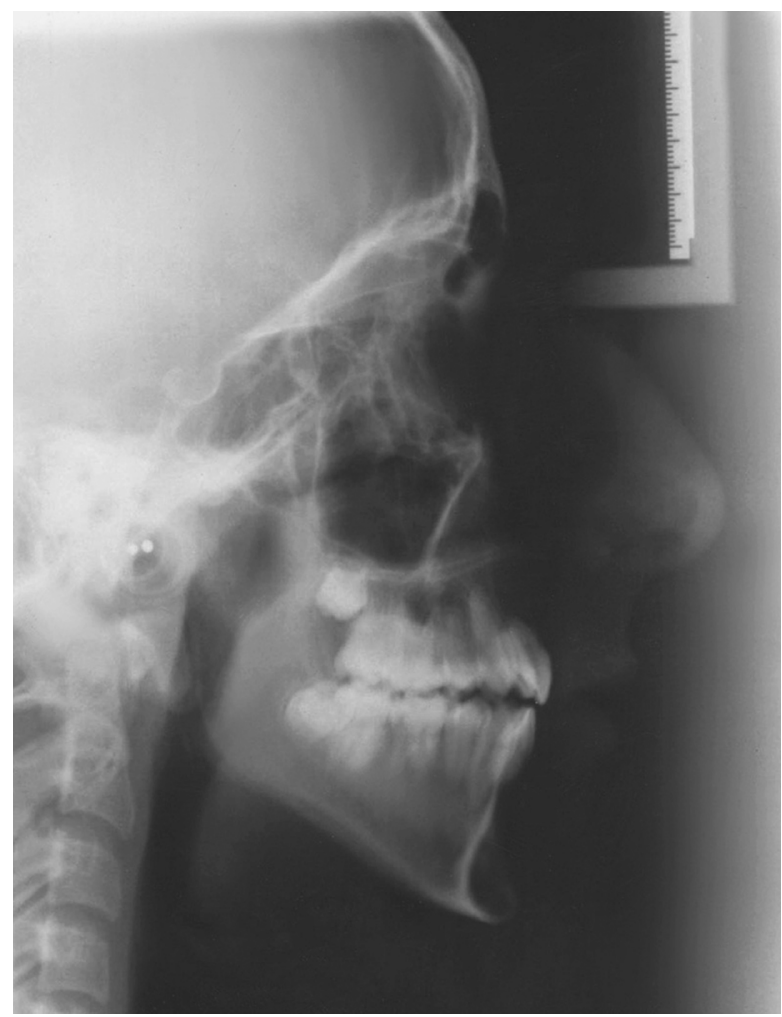

Figure 9. Post-treatment cephalometric x-ray, taken in 1994. relapse. A short course of fixed appliance therapy was planned and restarted in 1995 at the age of sixteen. After a while, the patient moved to another city for his education and presented to a private orthodontist to continue his treatment. The new orthodontist did not obtain x-rays or the patient's previous dental records. Intraoral elastics were used for a long time period to close the open bite. The treatment was terminated before completion as a result of the diagnosis of severe ARR, using x-rays taken at the university hospital in 2001 (Figures 10,11). Upper and lower fixed retainers were subsequently bonded, and the patient was submitted to followup (Figure 12). The last records of the patient were taken using CBCT at the University of Alabama Department of Orthodontics (Figures 13,14).

\section{DISCUSSION}

Orthodontic treatment-related risk factors include a prolonged treatment time, the direction of force and tooth movement, and the type of force application. ${ }^{2}$ In this study, the potential patient-related risk factors of ARR were observed to be an allergic constitution and the severity of malocclusion.

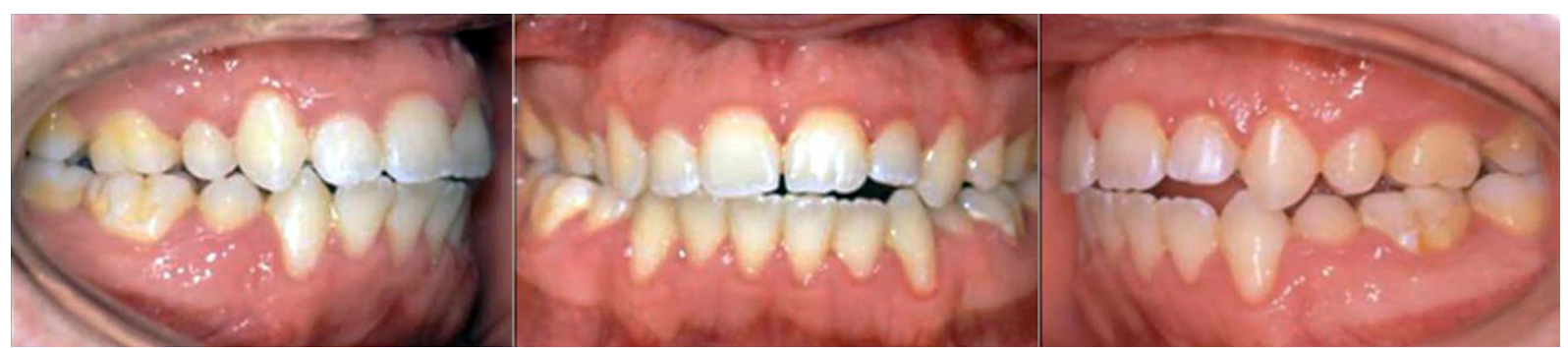

Figure 10. Intraoral photographs taken after last debonding in 2001

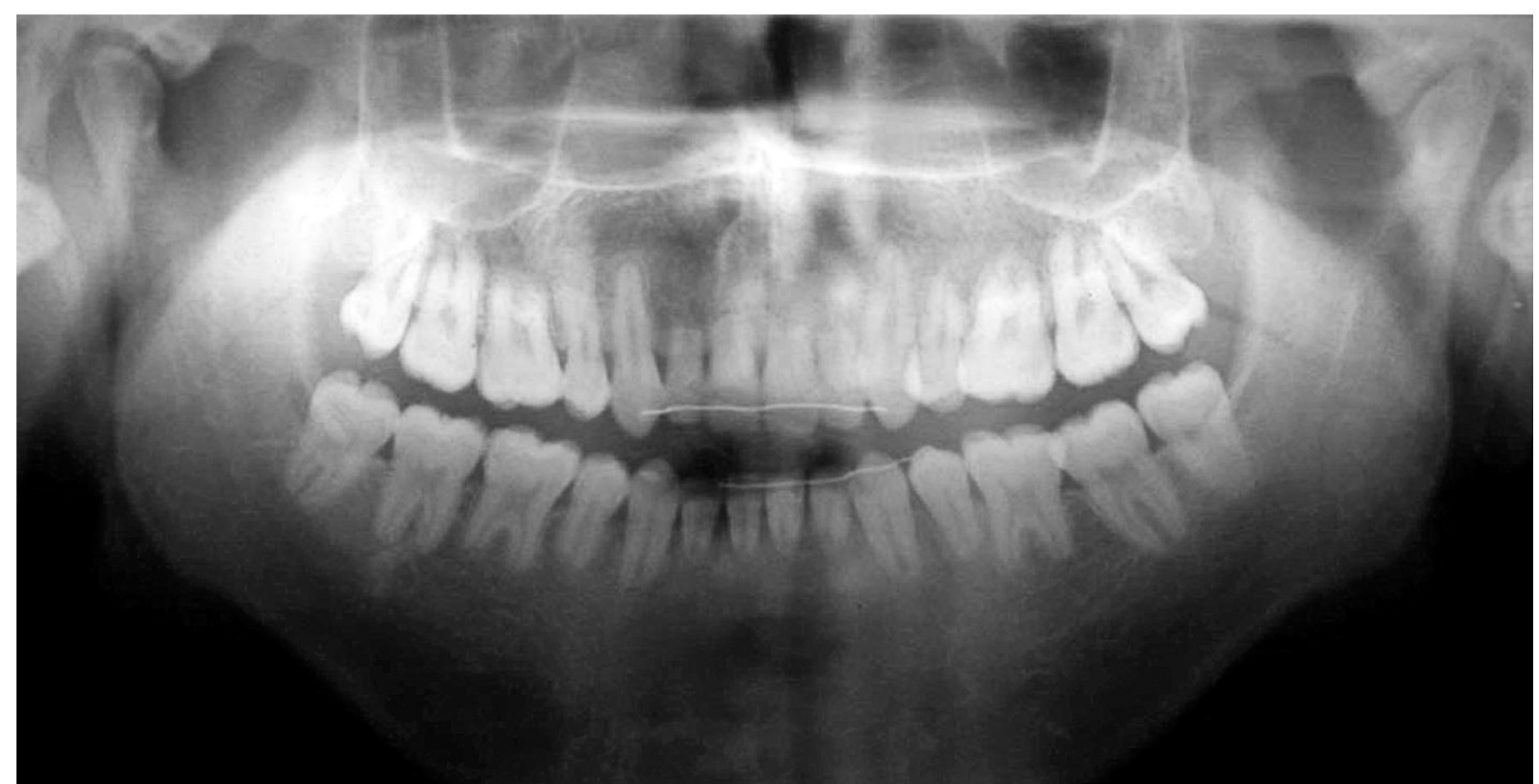

Figure 11. Panoramic x-ray, taken in 2001. 
These characteristics are applicable to a susceptible patient. In addition, a previous history of root resorption might have contributed to the aggressive progress of ARR during the second fixed appliance therapy.

Han et $a^{18}$ recommended that every clinician should be aware of the extrusion of teeth that might also cause root resorption in susceptible patients. In this patient, the long-term extrusive forces led to severe ARR. The literature indicates that jiggling ${ }^{26,27}$ and movement caused by the application of intermaxillary elastics ${ }^{8,28}$ are two types of movement that are likely to increase the risk of root resorption. When considering the maxillary central

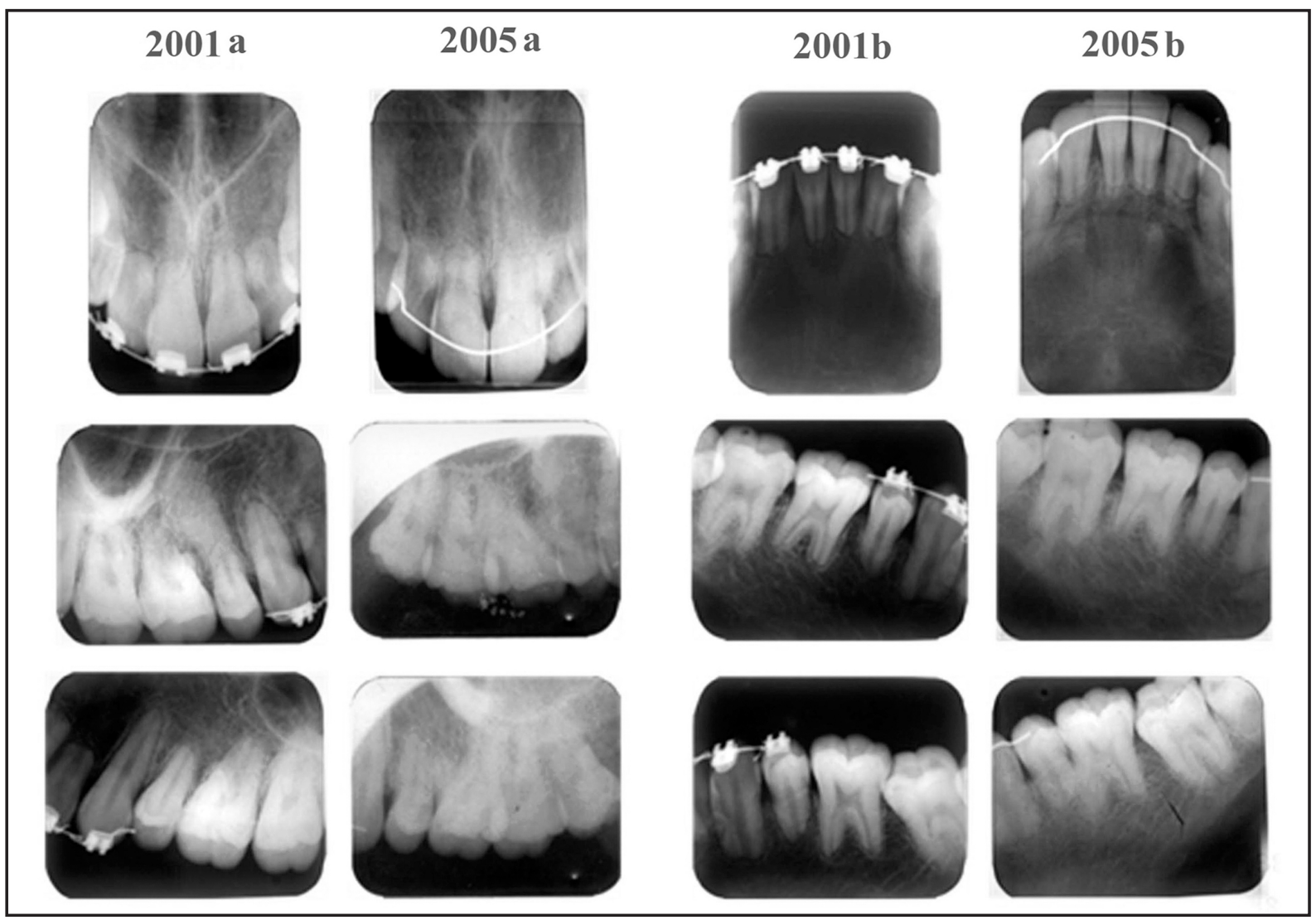

Figure 12. (2001 a-b, 2005 a-b) Comparison of the periapical radiographs in 2001 and 2005. Maxillary teeth are shown in columns 2001a and 2005a, and mandibular teeth are shown in columns $2001 \mathrm{~b}$ and $2005 \mathrm{~b}$.

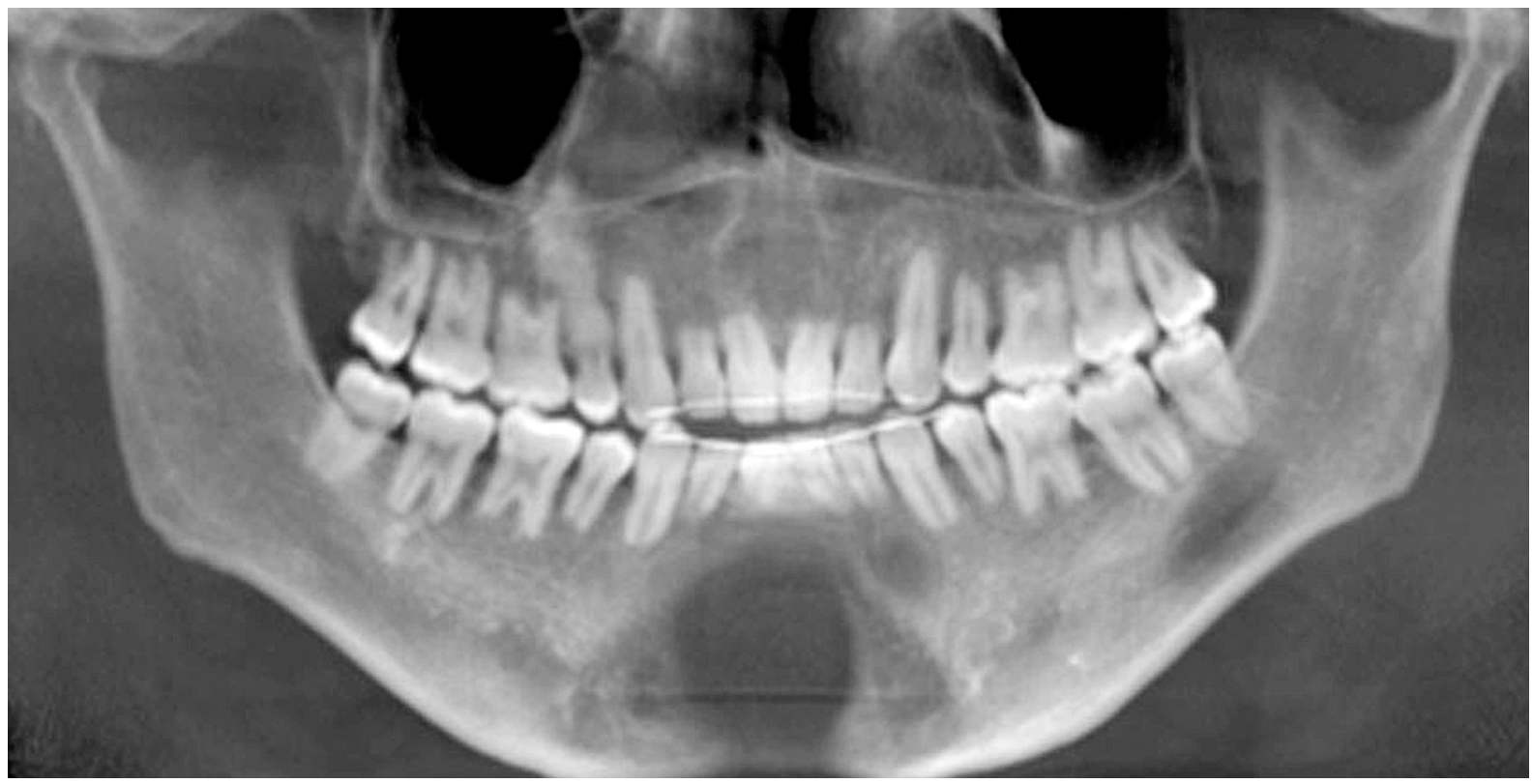

Figure 13. Last panoramic $x$-ray, taken in 2010, the patient was 31 years old. 
incisors, Weltman et $\mathrm{al}^{2}$ indicated that movements that rotate the apex lingually are strongly correlated with root resorption. We observed that intermaxillary vertical elastics were used to close the gap between the upper and lower anterior teeth. Additionally, we thought that palatinal root torque must have been applied on the maxillary incisors during incisor retraction and the closure of extraction spaces.

Among all teeth, the maxillary incisors show the most ARR, followed by the mandibular incisors and first molars. ${ }^{2}$ Remington et al ${ }^{29}$ concluded that maxillary incisors seem to be affected more frequently and to a more severe extent than the rest of the dentition. In accordance with these findings, in this patient, the most affected teeth were the upper and lower incisors, followed by the first molars. However, the premolars and lower canines were also considerably affected by severe ARR after the second orthodontic treatment. Further progression of ARR was not observed after the therapy was finally terminated. Nevertheless, smoothing at the root tips was noticed in followup radiographic records over time. The literature supports the present findings and indicates that ARR associated with orthodontic forces does not progress after active orthodontic treatment ends; in fact reparative processes take place after the cessation of treatment, including smoothing and remodeling of sharp edges. ${ }^{29}$ There have been speculations that severely resorbed teeth have low resistance to masticatory functional loads, and that functional forces may lead to further ARR. ${ }^{29}$ However, our clinical and radiologic observations suggest that even severely resorbed teeth appeared to function in a reasonable manner and that ARR did not progress in the years after orthodontic intervention.

The literature indicates that the apical part of the root has relatively minor importance for total periodontal support, and approximately $3 \mathrm{~mm}$ of apical root loss is equivalent to $1 \mathrm{~mm}$ of crestal bone loss. 2,29 In an investigation in which 100 patients were reexamined 14 years after orthodontic treatment, tooth loss and hypermobility were found in only 2 samples. ${ }^{29}$ Similarly, in a more recent study, patients who had experienced severe ARR were recalled 5-15 years after treatment; no teeth were found to have mobility scores greater than 1 on Miller's index lcrown deviations within $1 \mathrm{~mm}$ of normal position), and no teeth had been lost.30 Accordingly, neither tooth loss nor increased mobility was observed in this study. The patient was not aware of his ARR until the final debonding.

Segal et al ${ }^{21}$ concluded that the total treatment duration is highly correlated with ARR. Similarly, in this study the very long treatment time was thought to be another factor that had a detrimental effect on severe ARR. If we exclude the nearly one year break between the years 1994-1995, the total active treatment time was almost 10 years from the beginning of fixed appliance therapy in 1991 until the termination of the second treatment in 2001. A considerable increase in ARR was observed in the final radiographs obtained from the first fixed appliance therapy and from the second fixed appliance therapy, which spanned an interval of six years.

The severity of root resorption cannot be accurately judged from radiographs alone. Heimisdottir et $\mathrm{al}^{31}$ indicated that from both clinical and forensic points of view, CBCT scans should be performed whenever suspicion arises that the roots could be moderately to severely resorbed. The CBCT images of this patient show more clearly the degree of severity of ARR and the geometry of the resorption.

Field et $a^{32}$ were recently able to fabricate a computer model of strain distribution in a multitooth model. The authors suggested that the de-

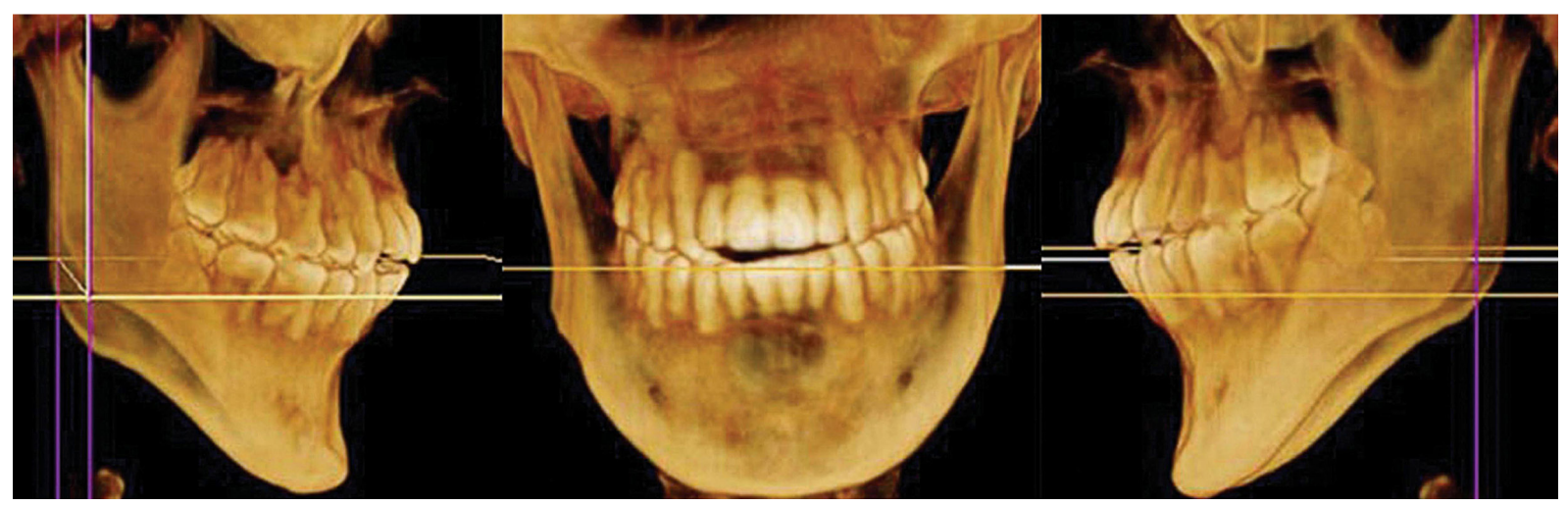

Figure 14. Anterior and lateral CBCT images, taken in 2010. 
velopment of complex mathematical models, using experimentally determined material and anatomic data to depict a realistic clinical situation, might lead to a more accurate means of predicting biologic reactions and might subsequently improve clinical outcomes. In this way, clinicians may be able to predict the undesirable outcomes of their treatment, and to personalize orthodontic treatment approaches in the near future. Furthermore, with increases in genomic research on the SNPs of genes related to root resorption, it may be possible to predict any tendency for root resorption before beginning orthodontic treatment.

\section{Preventive Measures for Clinical Practice}

When you acquiring a new patient who has already begun orthodontic treatment and does not have his/her records, clinicians must not forget to obtain a new radiograph to assess root resorption before further treatment. A satisfactory anamnesis of the patient and family can help identify any risky situations or predispositions. It is important to inform orthodontic patients about the risks before treatment, and if ARR occurs, the patient must be informed about the situation.

Strong evidence suggests that comprehensive orthodontic treatment causes increased root resorption, and heavy forces have especially harmful effects. ${ }^{2}$ It is fervently recommended to apply light forces in orthodontic treatments and to leave longer intervals between activations. ${ }^{2}$ Serial radiographs obtained after 6-12 months might help to detect early root resorption, and if resorption is identified, a two to three month pause in treatment with a passive arch wire might help to prevent further resorption. ${ }^{2}$ In addition the treatment plan should be reviewed in such situations and possible therapeutic solutions, including prosthetic restorations, should be considered to terminate orthodontic forces as soon as possible.

After debonding, passively prepared fixed retention wires should be bonded carefully. Patients should be informed about maintaining their oral hygiene, as periodontitis may progress more rapidly in teeth with ARR. ${ }^{33}$

\section{REFERENCES}

1. Mohandesan $H$, Ravanmehr $H$, Valaei N. A radiographic analysis of external apical root resorption of maxillary incisors during active orthodontic treatment. Eur J Orthod 2007;29:134-139.
2. Weltman B, Vig KWL, Fields HW, Shanker S, Kaizer EE. Root resorption associated with orthodontic tooth movement: A systematic review. Am J Orthod Dentofacial Orthop 2010;137:462-476.

3. Harris EF, Robinson QC, Woods MA. An analysis of causes of apical root resorption in patients not treated orthodontically. Quintessence Int 1993;24:417-428.

4. Killiany DM. Root resorption caused by orthodontic treatment: an evidence-based review of literature. Semin Orthod 1999;5:128-133.

5. Lee KS, Straja SR, Tuncay OC. Perceived long-term prognosis of teeth with orthodontically resorbed roots. Orthod Craniofac Res 2003;6:177-191.

6. Brezniak N, Wasserstein A. Orthodontically induced inflammatory root resorption. Part I: Basic science aspect. Angle Orthod 2002;72:175-179.

7. Al-Qawasmi RA, Hartsfield JK, Evrett ET, Flury L, Liu L, Foroud TM, Macri JV, Roberts WE. Genetic predisposition to external apical root resorption. Am J Orthod Dentofacial Orthop 2003;123:242-252.

8. Levander E, Malmgren O, Stenback K. Apical root resorption during orthodontic treatment of patients with multiple aplasia: a study of maxillary incisors. Eur J Orthod 1998;20:427-434.

9. Harry MR, Sims MR. Root resorption in bicuspid intrusion. A scanning electron microscope study. Angle Orthod 1982;52:235-258.

10. Kokich VG. Orthodontic and nonorthodontic root resorption: their impact on clinical dental practice. J Dent Educ 2008;72:895-902.

11. Marques LS, Ramos-Jorge ML, Rey AC, Armond MC, Oliveira Ruellas AC. Severe root resorption in orthodontic patients treated with the edgewise method: Prevalence and predictive factors. Am J Orthod Dentofacial Orthop 2010;137:384-388

12. Dudic A, Giannopoulou C, Leuzinger M, Kiliaridis S. Detection of apical root resorption after orthodontic treatment by using panoramic radiography and cone-beam computed tomography of super-high resolution. Am J Orthod Dentofacial Orthop 2009;135:434-437.

13. Harris DA, Jones AS, Darendeliler MA. Physical properties of root cementum: part 8 . Volumetric analysis of root resorption craters after application of controlled intrusive light and heavy orthodontic forces: a microcomputed tomography scan study. Am J Orthod Dentofacial Orthop 2006;130:639-647. 
14. Barbagallo LJ, Jones AS, Petocz P, Darendeliler MA. Physical properties of root cementum: part 10. Comparison of the effects of invisible removable thermoplastic appliances with light and heavy orthodontic forces on premolar cementum. Amicrocomputed-tomography study. Am J Orthod Dentofacial Orthop 2008;133:218-227.

15. Chan E, Darendeliler MA. Physical properties of root cementum: part 5. Volumetric analysis of root resorption craters after application of light and heavy orthodontic forces. Am J Orthod Dentofacial Orthop 2005;127:186-195.

16. Chan E, Darendeliler MA. Physical properties of root cementum: part 7. Extent of root resorption under areas of compression and tension. Am J Orthod Dentofacial Orthop 2006;129:504-510.

17. Chan EKM, Darendeliler MA. Exploring the third dimension in root resorption. Orthod Craniofacial Res 2004;7:64-70.

18. Han G, Huang S, Von den Hoff JW, Zeng X, KuijpersJagtman AM. Root resorption after orthodontic intrusion and extrusion: an intraindividual study. Angle Orthod 2005;75:912-918.

19. Parker RJ, Harris EF. Directions of orthodontic tooth movements associated with external apical root resorption of the maxillary central incisor. Am J Orthod Dentofacial Orthop 1998;114:672-683.

20. Costopoulos G, Nanda R. An evaluation of root resorption incident to orthodontic intrusion. Am J Orthod Dentofacial Orthop 1996;109:543-548.

21. Segal G, Shiffman P, Tuncay O. Meta analysis of the treatment related factors of external apical root resorption. Orthod Craniofacial Res 2004;7:71-78.

22. Levander E, Malmgren O, Eliasson S. Evaluation of root resorption in relation to two orthodontic treatment regimes. A clinical experimental study. Eur J Orthod 1994;16:223228.

23. Acar A, Canyurek U, Kocaaga M, Erverdi N. Continuous vs. discontinuous force application and root resorption. Angle Orthod 1999;69:159-164.

24. Oppenhiem A. Human tissue response to orthodontic intervention of short and long duration. Am $J$ Orthod 1942;28:263-301

25. Reitan K. Some factors determining the evaluation of forces in orthodontics. Am J Orthod 1957;43:32-47.

26. Baumrind S, Korn EL, Boyd RL. Apical root resorption in orthodontically treated adults. Am J Orthod Dentofacial Orthop 1996;110:311-320.

27. Proffit WR, Fields HW. The first stage of comprehensive treatment: alignment and leveling. In: Proffit WR, Fields HW, Sarver DM (ed). Contemporary Orthodontics. 3rd ed. St Louis: C.V. Mosby, 2000:527-529.
28. Mirabella AD, Artun J. Risk factors for apical root resorption of maxillary anterior teeth in adult orthodontic patients. Am J Orthod Dentofacial Orthop 1995;108:48-55.

29. Remington DN, Joondeph DR, Artun J, Riedel RA, Chapko MK. Long-term evaluation of root resorption occuring during orthodontic treatment. Am J Orthod Dentofacial Orthop $1989 ; 96: 43-46$.

30. Levander E, Malmgren O. Long-term follow-up of maxillary incisors with severe apical root resorption. Eur $J$ Orthod 2000;22:85-92

31. Heimisdottir K, Bosshardt D, Ruf S. Can the severity of root resorption be accurately judged by means of radiographs? A case report with histology. Am J Orthod Dentofacial Orthop 2005;128:106-109.

32. Field C, Ichim I, Swain MV, Chan E, Darendeliler MA, Li W, Li Q. Mechanical responses to orthodontic loading: A 3-dimensional finite element multi-tooth model. Am J Orthod Dentofacial Orthop 2009;135:174-181.

33. Kalkwarf KL, Krejci RF, Pao YC. Effect of apical root resorptionon periodontal support. J Prosthet Dent 1986;56:317319. 